\title{
Rickettsia vini n. sp. (Rickettsiaceae) infecting the tick Ixodes arboricola (Acari: Ixodidae)
}

\author{
Marketa Novakova ${ }^{1,2^{*}}$ D, Francisco B. Costa ${ }^{3}$, Frantisek Krause ${ }^{4}$, Ivan Literak ${ }^{1,2}$ and Marcelo B. Labruna ${ }^{3}$
}

\begin{abstract}
Background: Recently, a new rickettsia named 'Candidatus Rickettsia vini' belonging to the spotted fever group has been molecularly detected in Ixodes arboricola ticks in Spain, the Czech Republic, Slovakia and Turkey, with prevalence reaching up to $100 \%$. The aim of this study was to isolate this rickettsia in pure culture, and to describe it as a new Rickettsia species.

Methods: A total of 148 ornitophilic nidicolous ticks Ixodes arboricola were collected in a forest near Breclav (Czech Republic) and examined for rickettsiae. Shell vial technique was applied to isolate rickettsiae in Vero cells. Rickettsial isolation was confirmed by optical microscopy and sequencing of partial sequences of the rickettsial genes glt $A$, ompA, ompB, and htrA. Laboratory guinea pigs and chickens were used for experimental infestations and infections. Animal blood sera were tested by immunofluorescence assay employing crude antigens of various rickettsiae.

Results: Rickettsia vini $\mathrm{n}$. sp. was successfully isolated from three males of I. arboricola. Phylogenetic analysis of fragments of 1092, 590, 800, and 497 nucleotides of the gltA, ompA, ompB, and htrA genes, respectively, showed closest proximity of $R$. vini $\mathrm{n}$. sp. to Rickettsia japonica and Rickettsia heilongjiangensis belonging to the spotted fever group. Experimental infection of guinea pigs and chickens with $R$. vini led to various levels of cross-reactions of $R$. vini-homologous antibodies with Rickettsia rickettsii, Rickettsia parkeri, 'Candidatus Rickettsia amblyommii', Rickettsia rhipicephali, Rickettsia bellii, and Rickettsia felis. Laboratory infestations by $R$. vini-infected I. arboricola larvae on chickens led to no seroconversion to $R$. vini n. sp., nor cross-reactions with $R$. rickettsii, $R$. parkeri, 'Ca. R. amblyommii', R. rhipicephali, R. bellii or $R$. felis.

Conclusions: Our results suggest that $R$. vini n. sp. is possibly a tick endosymbiont, not pathogenic for guinea pigs and chickens. Regarding specific phenotypic characters and significant differences of DNA sequences in comparison to the most closely related species ( $R$. japonica and $R$. heilongjiangensis), we propose to classify the isolate as a new species, Rickettsia vini.
\end{abstract}

Keywords: Ticks, Ixodes arboricola, Tree-hole tick, Ixodidae, Ornitophilic ticks, Nidicolous ticks, Rickettsia vini, Rickettsiae, Spotted fever group, Czech Republic

\footnotetext{
* Correspondence: novakova.marke@gmail.com

'Department of Biology and Wildlife Diseases, Faculty of Veterinary Hygiene

and Ecology, University of Veterinary and Pharmaceutical Sciences Brno,

Brno, Czech Republic

${ }^{2}$ CEITEC, University of Veterinary and Pharmaceutical Sciences Brno, Brno,

Czech Republic

Full list of author information is available at the end of the article
} 


\section{Background}

Rickettsiae are Gram-negative coccobacilli belonging to the family Rickettsiaceae, order Rickettsiales in the alpha subdivision of the class Proteobacteria. Rickettsia spp. have small genomes (1.1-2.1 Mb) resulted from reductive evolution caused by their obligate endosymbiotic relationship to eukaryotic cells [1]. Their host diversity is remarkably high. Although all valid species are associated with arthropods, novel genotypes have also been identified in annelids, amoebae and plants [2, 3]. A number of Rickettsia species can propagate in vertebrates, some of them cause diseases in humans and animals, to which they are transmitted by arthropod vectors such as fleas, lice, mites or ticks. Some species are considered non-pathogenic, and novel Rickettsia species reveal to be nearly cosmopolitan [4].

Originally, pathogenic rickettsiae used to be divided into two groups, the typhus group that included Rickettsia prowazekii and Rickettsia typhi, and the spotted fever group (SFG) composed by about 20 species [5]. The taxonomic position of other rickettsial species has remained unclear because of their genetic anomalies. Due to findings of intriguing variety of rickettsiae in arthropods and molecular analysis of rickettsial plasmids, the genus Rickettsia has been reclassified into SFG rickettsiae, typhus group rickettsiae, the transitional group, the Rickettsia bellii group, the Rickettsia canadensis group, and several basal groups [3, 6]. However, some authors do not support the creation of the transitional group claiming that it is not monophyletic and is unhelpful as it does not take into account epidemiological criteria [1].

Tick-borne rickettsioses are caused by rickettsiae belonging to the SFG [4]. Rapid development of molecular methods brought reversed approach to tick-borne pathogen research, when disease cases are detected years after the tick-borne microorganism was first discovered [7]. There have been species of rickettisae detected in ticks years or decades before they became associated with human illness cases, e.g. Rickettsia monacensis, Rickettsia parkeri, Rickettsia massiliae and Rickettsia slovaca $[4,8]$. It is not clear if these novel tick-borne diseases were not noticed by physicians or whether they were absent. While it has been suggested that any novel described rickettsia from ticks should be considered a potential pathogen [5], many tick species just do not bite humans under natural conditions, or some rickettsial agents are just tick endosymbionts.

Recently, a novel SFG rickettsia has been found by molecular methods in bird-associated ticks. It was named 'Candidatus Rickettsia vini' and until now it has been detected in Spain, the Czech Republic, Slovakia and Turkey [9-11]. This bacterium has been molecularly detected mainly in Ixodes arboricola ticks, in which the prevalence is high (reaching 90-100 \%) [11, 12]. It has rarely been found in immature stages of Ixodes ricinus [9]. I. arboricola tick is widely distributed in the Palaearctic region. It lives in tree holes and nest boxes where it feeds on hole-breeding birds. Although this tick species does not represent a primary risk for humans, it shares several host species and overlaps in feeding period with Ixodes ricinus [13]. Therefore, tickborne microorganisms, including ' $\mathrm{Ca}$. R. vini', could be potentially bridged between these two tick species via cofeeding. Phylogenetic analysis based on partial sequences of four rickettsial genes $(g l t A, o m p A, o m p B, s c a 4)$ showed that ' $C a$. R. vini' segregated closest to Rickettsia heilongiangensis and Rickettsia japonica, supported by high bootstrap values [14]. The latter two species are causative agents of the Far East spotted fever ( $R$. heilongjiangensis) and the Japanese spotted fever ( $R$. japonica), and both have been reported in Asia [4].

In order to describe ' $\mathrm{Ca}$. R. vini' as a new species, we isolated the bacterium in cell culture for the first time, and performed both molecular and phenotypical characterization of the isolates.

\section{Methods}

\section{Field study in Breclav, Czech Republic}

Free-living $I$. arboricola ticks were collected manually from nest boxes during after-breeding season in Breclav, Czech Republic ( $48^{\circ} 43^{\prime} \mathrm{N}, 16^{\circ} 54$ 'E, $150 \mathrm{~m}$ above sea level, an oak-ash flood-plain forest), an area attractive to tourists. Nesting bird species had been previously identified during the breeding season using a bird guide book [15] and confirmed according to characteristic appearance of the nest during tick collecting. Ticks were identified to species according to Nosek \& Sixl [16]. Collected ticks were brought alive to the laboratory and incubated at $12{ }^{\circ} \mathrm{C}$ (relative humidity of $80 \%$ ) for 3 months and then at $24{ }^{\circ} \mathrm{C}$ (relative humidity of $80 \%$ ) for 7 days before being subjected to the hemolymph test.

\section{Hemolymph test and isolation of rickettsiae}

Selected individuals were tested for the presence of Rickettsia-like structures using the hemolymph test [17]. Shortly, the distal part of a tick leg was cut, then a drop of hemolymph was dried on a microscope slide and stained using Gimenez method [18]. The whole-body remnants were immediately stored at $-80{ }^{\circ} \mathrm{C}$ to preserve living rickettsial organisms.

Isolation of rickettsiae from the tick samples was performed according to previous protocols [19] with some modifications. Briefly, ticks were surface-sterilized by immersion in iodine-alcohol for $10 \mathrm{~min}$, washed in sterile water, macerated, and resuspended in $600 \mu \mathrm{l}$ of brain heart infusion (BHI). For each tick sample, two shell vials with a confluent monolayer of Vero cells were each inoculated with $300 \mu \mathrm{l}$ of the BHI suspension and then centrifuged for $1 \mathrm{~h}$ at $700 \times g$ and $22{ }^{\circ} \mathrm{C}$. The monolayers were washed 
and fed with $1 \mathrm{ml}$ of minimal essential medium supplemented with $5 \%$ of bovine calf serum (Hyclone, Logan, UT, USA) and $1 \%$ of antibiotics and antifungal (penicillin, streptomycin and amphotericin B) and incubated at $28^{\circ} \mathrm{C}$. Every 3 days, the medium was replaced by a new medium (without antibiotics and antifungal additives), and the aspirated medium was checked for the presence of Rickettsia-like organisms by Gimenez staining. If the result was positive, the monolayer of the shell vial was harvested and inoculated into a $25 \mathrm{~cm}^{2}$ flask containing a monolayer of confluent uninfected Vero cells. Cells in the $25 \mathrm{~cm}^{2}$ flask were checked by Gimenez staining until $>90 \%$ of them were infected, when they were harvested and inoculated into $75 \mathrm{~cm}^{2}$ flasks of Vero cells. The level of infection of cells was monitored by Gimenez staining of scraped cells from the inoculated monolayer. The rickettsial isolate was considered to be established in the laboratory after at least three passages through $75 \mathrm{~cm}^{2}$ Vero cell flasks, each achieving a proportion $>90 \%$ of infected cells [20].

\section{Experimental infestations and inoculations}

Selected larvae obtained from one egg cluster of I. arboricola were PCR-tested to confirm the presence of rickettsial DNA. Then, three tick naive chickens (denoted A, B and C) were each infested with $100 \mathrm{I}$. arboricola larvae from this cluster. Blood samples were collected from the chickens at the beginning of the infestation (day 0 ) and 21 days later. Two chickens (denoted D, E) and two male guinea pigs (denoted A, B), all tick naive, were each inoculated intraperitoneally with a suspension of $\approx 1 \times 10^{6}$ Vero cells infected with an $I$. arboricola rickettsial isolate derived from a fresh culture containing $>90 \%$ infected cells. Blood samples were collected at 0 and 21 days after inoculation. The guinea pigs were examined daily for fever (if the rectal temperature was $>39.5^{\circ} \mathrm{C}$ ) and scrotal reactions.

\section{Serological tests}

Animal blood sera were individually tested by immunofluorescence assay (IFA) as described [21], employing crude antigens of five SFG rickettsiae (the I. arboricola rickettsial isolate Rv-M1A strain Breclav; Rickettsia rickettsii strain Taiaçu [22]; $R$. parkeri strain At24 [23]; 'Candidatus Rickettsia amblyommii' strain Ac37 [19]; and Rickettsia rhipicephali strain HJ5 [24]); a basal group rickettsia ( $R$. bellii strain Mogi [22]); and one transitional group rickettsia (Rickettsia felis strain Pedreira [25]), which were prepared using whole infected Vero or C6/36 cells as previously described [21]. Sera were diluted in 2-fold increments, beginning from a 1:64 dilution, tested with fluorescein isothiocyanate-labeled rabbit anti-guinea pig IgG (Sigma-Aldrich, St. Louis, MO, USA) or anti-bird IgG-FITC conjugate (Alpha Diagnostic Intl Inc., San Antonio, TX, USA). Endpoint titers for both homologous and heterologous reactions were determined.

\section{Molecular characterization}

All whole-body remnants of the ticks used to inoculate shell vials and infected Vero cell 1st-4th passages were subjected to DNA extraction using the guanidine isothiocyanate technique, as described elsewhere [26], and DNA extracts were stored at $-20{ }^{\circ} \mathrm{C}$ until they were used as templates for polymerase chain reaction (PCR). DNA samples were tested by a battery of PCR protocols targeting fragments of four rickettsial genes: citrate synthase gene (gltA), the 190-kDa outer membrane protein gene (ompA), the $120-\mathrm{kDa}$ outer membrane protein gene $(o m p B)$, and the $17-\mathrm{kDa}$ protein gene $(h \operatorname{tr} A)$ (Table 1$)$. Each PCR run included a negative control ( $2.5 \mu \mathrm{l}$ of water) and a positive control (2.5 $\mu \mathrm{l}$ of DNA of Rickettsia parkeri strain NOD) samples. PCR products were purified by ExoSAP-IT (USB), DNA-sequenced by Sanger dideoxy sequencing, and analyzed using BLAST [27] to determine similarities to other Rickettsia spp. available in GenBank, National Center for Biotechnology Information (NCBI) [28]. The DNA sequences obtained from the 4th passage-infected cells were submitted to the GenBank database (see below). Phylogenetic analyses were performed using the program MEGA version 6.06 in November 2015 [29]. The newly-generated partial DNA sequences (gltA, ompA, $o m p B$, and $h t r A$ genes) were analyzed separately, and also concatenated. In both cases, nucleotides were aligned with the corresponding sequences of other Rickettsia species available in the GenBank database using MUSCLE algorithm as implemented in MEGA. The resulted alignment was checked and manually corrected. The evolutionary history was inferred using the Maximum Likelihood method based on the Tamura 3-parameter $(\mathrm{I}+\mathrm{G})$ model with 1000 replicates of random-addition taxa and tree bisection and reconnection branch swapping. All positions were weighted equally.

\section{Morphology by light microscopy}

Gimenez stained hemolymph smears were examined under oil immersion (at magnification of $\times 1000$; 10 $\times$ ocular and a 100x objective). Images of Rickettsia-like structures and adjacent Vero cells were captured using Leica Microscope DM4000-B.

\section{Results \\ Family Rickettsiaceae Pinkerton 1936 \\ Genus Rickettsia da Rocha-Lima 1916}

\section{Rickettsia vini n. sp.}

Type-host: Tree-hole tick, Ixodes arboricola Schultze \& Schlottke, 1930 (Acari: Ixodida: Ixodidae).

Type-locality: Breclav, Czech Republic. 
Table 1 Primer pairs used for amplification of rickettsial genes

\begin{tabular}{|c|c|c|c|c|c|}
\hline \multicolumn{2}{|c|}{$\begin{array}{l}\text { Target gene, } \\
\text { primer pair no., } \\
\text { primer name }\end{array}$} & \multirow[t]{2}{*}{ Specifity } & \multirow[t]{2}{*}{ Sequence } & \multirow[t]{2}{*}{$\begin{array}{l}\text { Amplified } \\
\text { fragment (nt) }\end{array}$} & \multirow[t]{2}{*}{ Reference } \\
\hline glth & & & & & \\
\hline \multirow[t]{2}{*}{1} & CS-78 & & 5'-GCAAGTATCGGTGAGGATGTAAT-3' & 401 & [19] \\
\hline & CS-323 & & 5'-GCTTCCTTAAAATTCAATAAATCAGGAT-3' & & [19] \\
\hline \multirow[t]{2}{*}{2} & CS-239 & & 5'-GCTCTTCTCATCCTATGGCTATTAT-3' & 834 & [38] \\
\hline & CS-1069 & & 5'-CAGGGTCTTCGTGCATTTCTT-3' & & [38] \\
\hline \multicolumn{2}{|c|}{ ompA } & $\begin{array}{l}\text { Spotted f } \\
\text { group (SF }\end{array}$ & & & \\
\hline \multirow[t]{2}{*}{3} & $\operatorname{Rr} 190.70 p$ & & 5'-ATGGCGAATATTTCTCCAAAA-3' & 632 & [39] \\
\hline & $190-701$ & & 5'-GTTCCGTTAATGGCAGCATCT-3' & & [40] \\
\hline \multicolumn{2}{|c|}{$o m p B$} & Genus Ric & & & \\
\hline \multirow[t]{2}{*}{4} & 120-M59 & & 5'-CCGCAGGGTTGGTAACTGC-3' & 820 & [41] \\
\hline & $120-807$ & & 5'-CCTTTAAGATTACCGCCTAA-3' & & [41] \\
\hline \multicolumn{2}{|c|}{ htrA } & Genus Ric & & & \\
\hline \multirow[t]{2}{*}{5} & $17 k-5$ & & 5'-GCTTTACAAAATTCTAAAAACCATATA-3' & 549 & [38] \\
\hline & $17 k-3$ & & 5'-TGTCTATCAATTCACAACTTGCC-3' & & [38] \\
\hline
\end{tabular}

${ }^{a}$ Except for some species of basal groups (e.g. Rickettsia bellii)

Other localities: La Rioja, Spain; Kızlırmak Delta, Samsun, Turkey; Velky Kosir, Czech Republic; Ziar nad Hronom, Slovakia.

Type-strain: The type-strain Breclav $^{\mathrm{T}}$ from three I. arboricola male ticks, sampled in Breclav, Czech Republic $\left(48^{\circ} 43^{\prime} \mathrm{N}, 16^{\circ} 54^{\prime} \mathrm{E}\right)$ in a nest box of Ficedula albicollis, is deposited at the Rickettsial Collection of the Laboratory of Parasitic Diseases of the Faculty of Veterinary Medicine, University of São Paulo, São Paulo, Brazil (culture collection codes: Rv-M1A-3P; Rv-M2B-3P; Rv-M3B-3P), and the Rickettsial Collection of the Rickettsial Zoonoses Branch of the Centers for Disease Control and Prevention (CDC), Atlanta, GA, USA (culture collection codes: Rv-M1A-2P; Rv-M2B-2P; Rv-M3B-2P).

Vector: Unknown.

Representative DNA sequences: GenBank: partial sequences KT187394 (gltA gene); KT326194 (ompA gene); KT187395 (ompB gene); KT187396 (htrA gene).

Etymology: The name vini has been proposed by Palomar et al. [9] who first detected molecularly this bacterium at La Rioja, a vineyard region in Spain. District of Breclav, the type-locality, is also an important area of vine production in the Czech Republic.

\section{Description}

Rickettsia vini n. sp. is a Gram-negative, nonmotile, obligately intracellular bacterium. The organism has a typical bacillary morphology with binary fission. It grows at $28{ }^{\circ} \mathrm{C}$ on Vero cells in minimal essential medium with $5 \%$ bovine calf serum supplement (Fig. 1). Sequencing of $g l t A, o m p A, o m p B$, and $h \operatorname{tr} A$ genes implies that this bacterium is significantly different from all recognized rickettsial species. It belongs to the SFG and is most closely related to $R$. japonica and $R$. heilongjiangensis. Rickettsia vini n. sp. is not pathogenic for chickens and guinea pigs through intraperitoneal inoculation, although it induces seroconversion in these animals (see below). The pathogenicity of this bacterium for vertebrate hosts, including humans, remains to be elucidated.

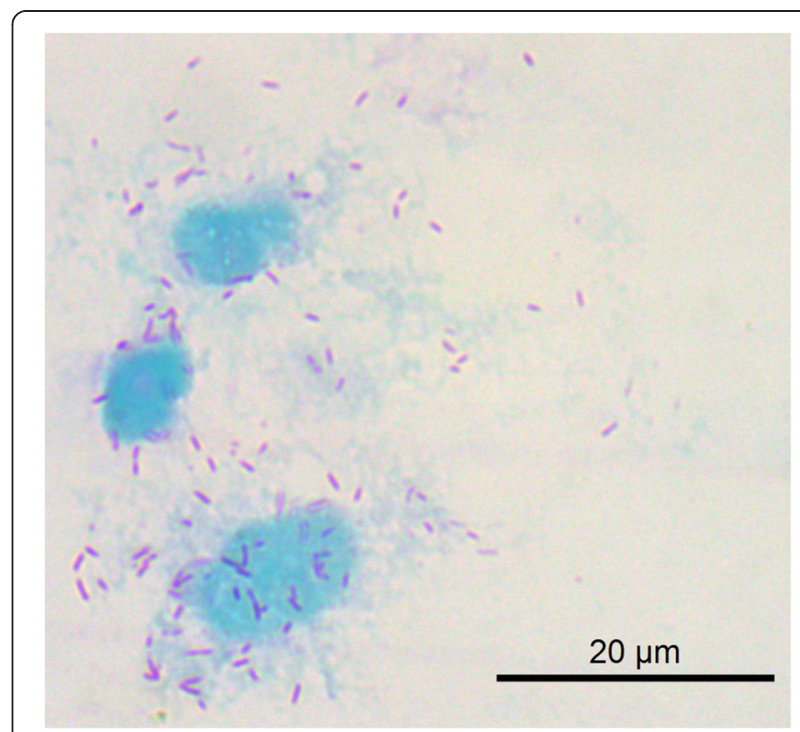

Fig. 1 Vero cells infected by Rickettsia vini n. sp. strain Breclav visualized by Gimenez staining 


\section{Field study}

A total of 35 nest boxes (32 of Ficedula albicollis, 3 of species of Paridae) were checked for the presence of ticks. One hundred forty-eight $I$. arboricola ticks (2 engorged nymphs, 18 males, 128 engorged females) were found in 9 (25.7\%) out of 35 nest boxes; all 9 boxes belonged to $F$. albicollis (arithmetic mean \pm standard error: $16.4 \pm 41.2$ ticks per infested nest box). Although one $F$. albicollis nest box contained 18 male and 115 engorged female ticks, all 6 nestlings successfully fledged, which was documented during breeding season. Ixodes arboricola females were each stored in a separate tube and egg clusters were laid by 24 of them. Hundreds of larvae hatched after one month.

\section{Isolation of Rickettsia vini n. sp.}

All 18 male ticks were subjected to the hemolymph test; of these three were found positive for Rickettsia-like organisms within their hemocytes, and subsequently subjected to the isolation of rickettsiae by the shell vial technique. Rickettsiae were successfully isolated from all three ticks and established in Vero cell culture (Fig. 1). The three isolates were designated as Rv-M1A, Rv-M2B, and Rv-M3B.

\section{Experimental infestations, inoculations and serological tests}

The chickens A, B and C that were infested with $R$. viniinfected $I$. arboricola larvae remained seronegative to all seven Rickettsia species, including $R$. vini antigens (Table 2). A total of 15 to 17 engorged larvae were recovered from each chicken. Conversely, the chickens D, E that were inoculated with $R$. vini-infected Vero cells showed seroconversion for $R$. vini n. sp., $R$. rickettsii, and ' $\mathrm{Ca}$. R. amblyommii' with titers ranging from 64 to 512 at 21 days after inoculation. Chicken $\mathrm{E}$ also seroconverted to $R$. bellii (Table 2). None of the above five chickens showed apparent signs of disease during the present study.
The guinea pig A showed seroconversion to $R$. vini, $R$. rickettsii and 'Ca. R. amblyommii' with 512, 512 and 256 endpoint titers, respectively, 21 days after intraperitoneal inoculation of $R$. vini-infected Vero cells. The guinea pig B seroconverted only to $R$. vini n. sp., with a 128 endpoint titer (Table 2). None of these guinea pigs developed fever, scrotal reactions or any other clinical alteration.

\section{Genotyping and phylogenetic analysis}

DNA of infected cells from the 1st to 4th rickettsial passages of all three isolates were tested by PCRs targeting the $g l t A, o m p A, o m p B$, and $h t r A$ genes, and 1092, 590, 800, and 497 nucleotides (nt), respectively, of the PCR products were sequenced from each isolate. Sequences obtained from different passages of all three isolates were $100 \%$ identical. BLAST analysis of the gltA partial sequence showed $100 \%(1092 / 1092 \mathrm{nt})$ similarity to the corresponding sequence of two strains of $R$. vini from the Czech Republic and Spain (KJ626330, JF803266) $[11,14]$. The ompA partial sequence revealed $100 \%(590 / 590 \mathrm{nt})$ similarity to the corresponding sequence of $R$. vini from Spain (JF758828) [14]. The ompB partial sequence showed $99.3 \%$ (764/769 nt) similarity to the corresponding sequence of Rickettsia sp. HIR/D91 (KC888953). The htrA partial sequence was 99.2\% (493/ $497 \mathrm{nt})$ similar to the corresponding sequence of various strains of $R$. rickettsii (AY281069, CP000766, CP000848, CP003305, CP003306, CP003307, CP003309, CP003311, CP003318, CP006009, CP006010, M28479) and Rickettsia philipii (CP003308). Before this study, there were no corresponding sequences of the $\operatorname{omp} B$ and the $h t r A$ gene fragments of $R$. vini in GenBank.

Phylogenetic analyses were inferred from the glt $A$, $o m p A$, ompB, and $h t r A$ partial sequences, with each gene analyzed separately (Additional files 1, 2, 3 and 4). Then an analysis of a concatenated dataset was carried out on an alignment that included 2979 nt $(1092,590,800$, 497 nt for the $g l t A, \operatorname{omp} A, \operatorname{omp} B$, and $h \operatorname{tr} A$ genes, respectively). In all analyses, $R$. vini n. sp. segregated

Table 2 Homologous and heterologous endpoint titers of IgG to seven Rickettsia species in animal sera

\begin{tabular}{|c|c|c|c|c|c|c|c|}
\hline \multirow[t]{2}{*}{ Species } & \multicolumn{3}{|c|}{ Chickens infested with $R$. vini-infected Ixodes arboricola } & \multicolumn{4}{|c|}{ Animals inoculated with $R$. vini culture } \\
\hline & Chicken A & Chicken B & Chicken C & Chicken D & Chicken E & Guinea pig A & Guinea pig B \\
\hline Rickettsia vini n. sp. & $-{ }^{a}$ & - & - & 128 & 512 & 512 & 128 \\
\hline Rickettsia rickettsii & - & - & - & 64 & 64 & 512 & - \\
\hline Rickettsia parkeri & - & - & - & - & - & - & - \\
\hline 'Ca. Rickettsia amblyommii' & - & - & - & 128 & 64 & 256 & - \\
\hline Rickettsia rhipicephali & - & - & - & - & - & - & NT \\
\hline Rickettsia bellii & - & - & - & - & 256 & - & - \\
\hline Rickettsia felis & - & - & - & - & - & - & - \\
\hline
\end{tabular}

a-, negative at the 1:64 serum dilution 
closest to $R$. japonica and $R$. heilongjiangensis cluster, which was supported by high bootstrap values (Fig. 2).

\section{Discussion}

This study described and characterized a new species of Rickettsia, $R$. vini n. sp., isolated from I. arboricola ticks collected in nest-boxes in the Czech Republic. This bacterium was first detected by PCR in I. arboricola and I. ricinus immature ticks collected from birds in La Rioja, a vineyard region in Spain [9] and named 'Ca. R. vini' [14]. To date, this bacterium has been detected molecularly in ticks in Europe and Turkey. The Palaearctic distribution of the type-species, the tick $I$. arboricola predicates possibly a similar wide occurrence of $R$. vini $\mathrm{n}$. sp.

Through molecular analyses (PCR detection), infection rates of $R$. vini in $I$. arboricola ticks up to $100 \%$ have been reported $[10,11,14]$; however, we found only three out of 18 males positive for Rickettsia-like organisms using the hemolymph test. This may be caused by higher sensitivity of PCR detection, when compared to the hemolymph test, or/and because not all $R$. vini-infected ticks contain rickettsiae in their hemolymph. All PCRtested unfed larvae of $I$. arboricola from this study contained rickettsial DNA, indicating transovarial transmission of the rickettsial agent.

All animals inoculated intraperitoneally seroconverted after 21 days, sometimes with high homologous antibody titers to $R$. vini n. sp. (Table 2). The guinea pig A showed cross-reactivity for $R$. rickettsii and ' $C a$. R. amblyommii' antigens, while the guinea pig $\mathrm{B}$ reacted only to the homologous antigens. Both chickens $\mathrm{D}$ and $\mathrm{E}$ inoculated with $R$. vini-infected Vero cells showed homologous titers always equal or higher than heterologous titers. Cross-reactivities were observed with closely related species belonging to the SFG such as $R$. rickettsii and ' $\mathrm{Ca}$. R. amblyommii', although chicken $\mathrm{E}$ also reacted to $R$. bellii, a non-SFG agent. Cross-reactivity with lower titres for heterologous antigens has also been observed in experimental studies with guinea pigs intraperitoneally inoculated by Vero cells infected with $R$. monteiroi, $R$. bellii, $R$. rickettsii or $R$. canandensis [30]. Although $R$. felis is phylogenetically closer than $R$. bellii to $R$. vini, no crossreactivity with $R$. felis was observed. These results indicate that $R$. vini $\mathrm{n}$. sp. possibly shares numerous antigenic constituents with other Rickettsia species, especially SFG members (Fig. 2). These findings are consistent with previous studies with mice, guinea pigs, dogs and opossums that were inoculated with different Rickettsia species [31-34].

Absence of clinical signs in $R$. vini-inoculated chickens $\mathrm{D}, \mathrm{E}$ and guinea pigs $\mathrm{A}, \mathrm{B}$ suggests that $R$. vini $\mathrm{n}$. sp. is not pathogenic for these animals. None of the three chickens A, B, C infested by $R$. vini-infected larvae seroconverted, in contrary to chickens $\mathrm{D}, \mathrm{E}$ that were inoculated with $R$. vini culture. While these results suggest a tick-symbiotical nature of $R$. vini, it is also possible that chickens (and guinea pigs) are just not susceptible to $R$. vini. If this is the case, the seroconversion of inoculated animals in the present study could be just a result of direct contact with bacterial antigens, rather than active

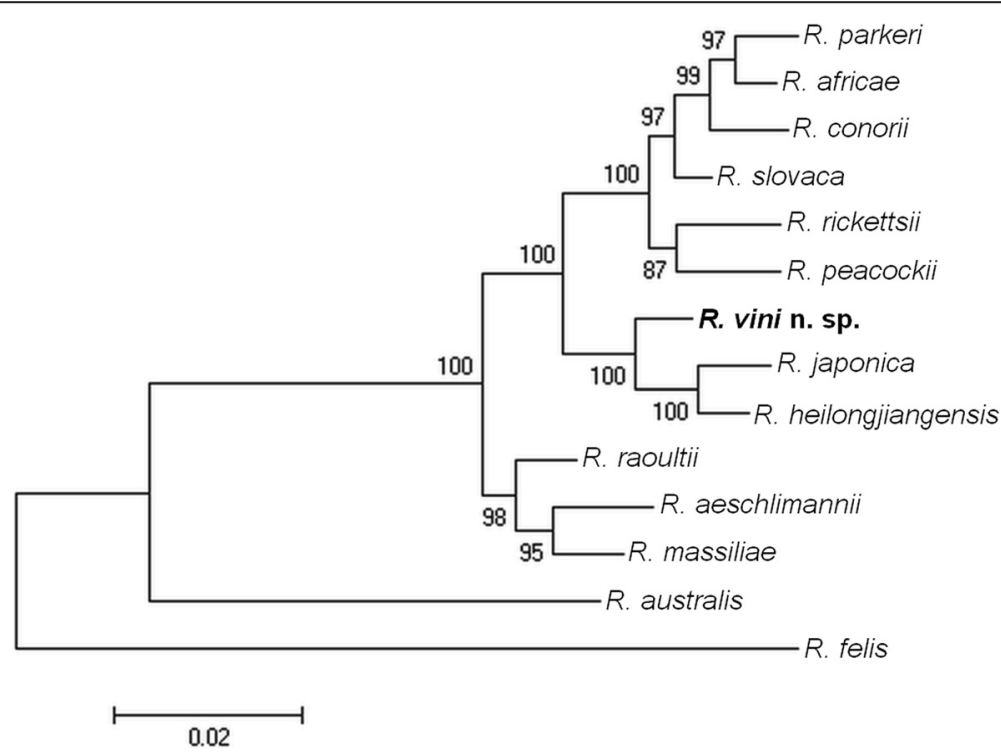

Fig. 2 Molecular phylogenetic analysis of Rickettsia vini n. sp. isolated from the tick Ixodes arboricola (Czech Republic). A total of 2979 unambiguously aligned nucleotide sites of the rickettsial genes gltA, ompA, ompB, and $h t r A$ were concatenated and subjected to analysis by the Maximum Likelihood method. The bootstrap values obtained by 1000 replicates are shown at the nodes. The tree is drawn to scale; scale-bar indicates nucleotide substitutions (\%) per site. The GenBank accession numbers of the sequences included in this analysis are shown in Additional files 1, 2, 3 and 4 
infection. Such assumptions need to be confirmed in further studies. Finally, the non-susceptibility of chickens in the present study could be linked to the inoculation route (intraperitoneal inoculation), since other rickettsial agents were shown to cause skin lesions through intradermal inoculations of experimental animals, in contrast to no clinical alterations when the same agents were intraperitoneally inoculated $[35,36]$. Moreover, our results of animal inoculations do not exclude a possible susceptibility of the bird hosts of $I$. arboricola to $R$. vini under natural conditions.

The phylogenetic analyses of four rickettsial genes showed that $R$. vini $\mathrm{n}$. sp. belongs to the SFG and is most closely related to $R$. japonica and $R$. heilongjiangensis, which is in compliance with previous studies $[11,14]$. In this study, we amplified different and longer fragments of the ompB and htrA genes of $R$. vini that have not been previously published. $R$. japonica and $R$. heilongjiangensis are associated with various tick vectors and mammal reservoirs [4]. It has been proposed that a new Rickettsia species should not show $>99.9 \%$, $>99.2 \%$, and $>98.8 \%$ similarity for the $g l t A, o m p B$, and ompA genes, respectively, with the most homologous validated species [37]. Similiarity values of $R$. vini DNA sequences with the most closely related validated species are $99.7 \%$ for the gltA gene of $R$. heilongjiangensis (CP002912), $96.8 \%$ for the ompB gene of $R$. japonica (AP011533), and $97.1 \%$ for the ompA gene of $R$. heilongjiangensis (CP002912). These comparison values also support the recognition of $R$. vini as a new species.

\section{Conclusions}

Here we report the first isolation of ' $\mathrm{Ca}$. R. vini' in cell culture, both molecular and morphological characterization of the isolates, experimental inoculation of laboratory guinea pigs and chickens, and experimental infestation of chickens with $R$. vini-infected ticks. We conclude that $R$. vini $\mathrm{n}$. sp. is not pathogenic for chickens and guinea pigs, although direct inoculation of these animals with $R$. vini resulted in seroconversion. The new species described here is ecologically, geographically and molecularly distinct from any closely related validated species.

\section{Additional files}

Additional file 1: Maximum Likelihood phylogenetic tree based on the partial gltA gene including a sequence for Rickettsia vini n. sp. (DOCX 637 kb)

Additional file 2: Maximum Likelihood phylogenetic tree based on the partial ompA gene including a sequence for Rickettsia vini n. sp. (DOCX 698 kb)

Additional file 3: Maximum Likelihood phylogenetic tree based on the partial ompB gene including a sequence for Rickettsia vini n. sp. (DOCX $639 \mathrm{~kb}$ )

Additional file 4: Maximum Likelihood phylogenetic tree based on the partial htrA gene including a sequence for Rickettsia vini n. sp. (DOCX 522 kb)

\section{Acknowledgments}

We thank to Amalia Barbieri, Fernanda Nieri-Bastos and Jonas Moraes-Filho for their help with cell culture and ricketsial antigens, and Jairo Mendoza Roldan for his help with image capture.

\section{Funding}

Marketa Novakova and Ivan Literak were supported by project CEITEC 2020 (LQ1601) from the Czech Ministry of Education, Youth and Sports within the National Programme for Sustainability II. Marcelo B. Labruna was supported by the "Coordenação de Aperfeiçoamento de Pessoal de Nível Superior" (CAPES, Brazil). The funders had no role in study design, data collection and interpretation, or the decision to submit the work for publication.

\section{Availability of data and materials}

The datasets supporting the conclusions of this article are included within the article and its additional files. The type-strain Breclav ${ }^{\top}$ is deposited at the Rickettsial Collection of the Laboratory of Parasitic Diseases of the Faculty of Veterinary Medicine, University of São Paulo, São Paulo, Brazil (culture collection codes: Rv-M1A-3P; Rv-M2B-3P; Rv-M3B-3P), and the Rickettsial Collection of the Rickettsial Zoonoses Branch of the Centers for Disease Control and Prevention (CDC), Atlanta, GA, USA (culture collection codes: Rv-M1A-2P; RvM2B-2P; Rv-M3B-2P)

\section{Authors' contributions}

MN contributed to conception of the study, collected and determined ticks used in this study, made molecular analysis of the rickettsial isolates, drafted the major part of the manuscript. FBC isolated the bacterium Rickettsia vini $\mathrm{n}$. sp. from Ixodes arboricola ticks, made serologic assays, experimental animal infestations and infections, drafted significant part of the manuscript, made final approval of the version to be published. FK collected samples for this study, determined the bird species, critically revised the manuscript and provided comments and suggestions, made final approval of the version to be published. IL contributed to conception of the study, critically revised the manuscript, provided comments and suggestions and made final approval of the version to be published. MBL designed and coordinated the experiments, contributed significantly to the manuscript by editing it, providing critical comments and suggestions, made final approval of the version to be published. All authors read and approved the final version of the manuscript.

\section{Competing interests}

The authors declare that they have no competing interests.

\section{Consent for publication}

Not applicable.

\section{Ethics approval and consent to participate}

This study was approved by the Ethics Committee on Animal Research for the Faculty of Veterinary Medicine of the University of São Paulo.

\section{Author details}

${ }^{1}$ Department of Biology and Wildlife Diseases, Faculty of Veterinary Hygiene and Ecology, University of Veterinary and Pharmaceutical Sciences Brno, Brno, Czech Republic. ${ }^{2}$ CEITEC, University of Veterinary and Pharmaceutical Sciences Brno, Brno, Czech Republic. ${ }^{3}$ Department of Preventive Veterinary Medicine and Animal Health, Faculty of Veterinary Medicine, University of São Paulo, São Paulo, Brazil. ${ }^{4}$ Breclav, Czech Republic.

Received: 17 March 2016 Accepted: 5 August 2016

Published online: 26 August 2016

References

1. Merhej $V$, Raoult D. Rickettsial evolution in the light of comparative genomics. Biol Rev. 2011;86:379-405.

2. Perlman SJ, Hunter MS, Zchori-Fein E. The emerging diversity of Rickettsia. Proc R Soc B. 2006;273:2097-106.

3. Weinert LA, Werren JH, Aebi A, Stone GN, Jiggins FM. Evolution and diversity of Rickettsia bacteria. BMC Biol. 2009;7:6

4. Parola P, Paddock CD, Socolovschi C, Labruna MB, Mediannikov O, Kernif T, et al. Update on tick-borne rickettsioses around the world: a geographic approach. Clin Microbiol Rev. 2013;26:657-702. 
5. Raoult D, Roux V. Rickettsioses as paradigms of new or emerging infectious diseases. Clin Microbiol Rev. 1997;10:694-719.

6. Gillespie JJ, Beier MS, Rahman MS, Ammerman NC, Shallom JM, Purkayastha A, et al. Plasmids and rickettsial evolution: Insight from Rickettsia felis. PLoS One. 2007;2:e266.

7. Tijsse-Klasen E, Koopmans MPG, Sprong H. Tick-borne pathogen - reversed and conventional discovery of disease. Front Public Health. 2014;2:73.

8. Jado I, Oteo JA, Aldámiz M, Gil H, Escudero R, Ibarra V, et al. Rickettsia monacensis and human disease, Spain. Emerg Infect Dis. 2007;13:1405-7.

9. Palomar AM, Santibáñez P, Mazuelas D, Roncero L, Santibáñez S, Portillo A, et al. Role of birds in dispersal of etiologic agents of tick-borne zoonoses, Spain, 2009. Emerg Infect Dis. 2012;18:1188-91.

10. Keskin A, Koprulu TK, Bursali A, Ozsemir AC, Yavuz KE, Tekin S. First record of Ixodes arboricola (Ixodida: Ixodidae) from Turkey with presence of Candidatus Rickettsia vini (Rickettsiales: Rickettsiaceae). J Med Entomol. 2014:51:864-7.

11. Novakova M, Bulkova A, Costa FB, Kristin A, Krist M, Krause F, et al. Molecular characterization of 'Candidatus Rickettsia vini' in Ixodes arboricola from the Czech Republic and Slovakia. Ticks Tick Borne Dis. 2015;6:330-3.

12. Palomar AM, Portillo A, Crespo A, Santibáñez S, Mazuelas D, Oteo JA Prevalence of 'Candidatus Rickettsia vini' in Ixodes arboricola ticks in the North of Spain, 2011-2013. Parasit Vectors. 2015;8:110.

13. Heylen DJA, Van Oosten AR, Devriendt N, Elst J, De Bruyn L, Matthysen E. Seasonal feeding activity of the tree-hole tick, Ixodes arboricola. Parasitology. 2014;141:1044-51.

14. Palomar AM, Portillo A, Santibáñez P, Santibáñez S, García-Álvarez L, Oteo JA. Genetic characterization of Candidatus Rickettsia vini, a new rickettsia amplified in ticks from La Rioja, Spain. Ticks Tick Borne Dis. 2012;3:318-20.

15. Svensson L, Mullarney K, Zetterström D. Birds of Europe. 2nd ed. New Jersey: Princeton University Press; 2010.

16. Nosek J, Sixl W. Central-European ticks (Ixodoidea) key for determination. Graz: Mitteilungen der Abteilung für Zoologie am Landesmuseum Joanneum; 1972. p. 1972

17. Burgdorfer W. Hemolymph test. A technique for detection of rickettsiae in ticks. Am J Trop Med Hyg. 1970;19:1010-4.

18. Gimenez DF. Staining rickettsiae in yolk-sac cultures. Stain Technol 1964;39:135-40.

19. Labruna MB, Whitworth T, Bouyer DH, McBride J, Camargo LMA, Camargo EP, et al. Rickettsia bellii and Rickettsia amblyommii in Amblyomma ticks from the state of Rondônia, Western Amazon, Brazil. J Med Entomol. 2004;41:1073-81.

20. Labruna MB, Whitworth T, Horta MC, Bouyer DH, McBride JW, Pinter A, et al. Rickettsia species infecting Amblyomma cooperi ticks from an area in the state of São Paulo, Brazil, where Brazilian spotted fever is endemic. J Clin Microbiol. 2004;42:90-8.

21. Horta MC, Labruna MB, Sangioni LA, Vianna MCB, Gennari SM, Galvão MAM, et al. Prevalence of antibodies to spotted fever group rickettsiae in humans and domestic animals in a Brazilian spotted fever-endemic area in the state of São Paulo, Brazil: Serologic evidence for infection by Rickettsia rickettsii and another spotted fever group Rickettsia. Am J Trop Med Hyg. 2004;71:93-7.

22. Pinter A, Labruna MB. Isolation of Rickettsia rickettsii and Rickettsia bellii in cell culture from the tick Amblyomma aureolatum in Brazil. Ann N Y Acad Sci. 2006:1078:523-30.

23. Silveira I, Pacheco RC, Szabó MPJ, Ramos HGC, Labruna MB. Rickettsia parkeri in Brazil. Emerg Infect Dis. 2007;13:1111-3.

24. Labruna MB, Pacheco RC, Richtzenhain $\amalg$, Szabó MPJ. Isolation of Rickettsia rhipicephali and Rickettsia bellii from Haemaphysalis juxtakochi ticks in the state of São Paulo, Brazil. Appl Env Microbiol. 2007;73:869-73.

25. Horta MC, Labruna MB, Durigon EL, Schumaker TTS. Isolation of Rickettsia felis in the mosquito cell line C6/36. Appl Environ Microbiol. 2006;72:1705-7.

26. Chomkzynski P. A reagent for the single-step simultaneous isolation of RNA, DNA and proteins from cell and tissue samples. Biotechniques. 1993;15:532-7.

27. Altschul SF, Gish W, Miller W, Myers EW, Lipman DJ. Basic local alignment search tool. J Mol Biol. 1990;215:403-10.

28. Geer LY, Marchler-Bauer A, Geer RC, Han L, He J, He S, Liu C, Shi W, Bryant SH. The NCBI BioSystems database. Nucleic Acids Res. 2010;38:D492-6. http://ncbi.nlm.nih.gov Accessed Nov. 2015.

29. Tamura K, Stecher G, Peterson D, Filipski A, Kumar S. MEGA6: Molecular evolutionary genetics analysis version 6.0. Mol Biol Evol. 2013:30:2725-9.

30. Pacheco RC, Moraes-Filho J, Marcili A, Richtzenhain LJ, Szabó MPJ, Catroxo $\mathrm{MHB}$, et al. Rickettsia monteiroi sp. nov., infecting the tick Amblyomma incisum in Brazil. Appl Environ Microbiol. 2011;77:5207-11.
31. Horta MC, Sabatini GS, Moraes-Filho J, Ogrzewalska M, Canal RB, Pacheco $\mathrm{RC}$, et al. Experimental infection of the opossum Didelphis aurita by Rickettsia felis, Rickettsia bellii, and Rickettsia parkeri and evaluation of the transmission of the infection to ticks Amblyomma cajennense and Amblyomma dubitatum. Vector Borne Zoonotic Dis. 2010;10:959-67.

32. Philip RN, Casper EA, Burgdorfer W, Gerloff RK, Hughes LE, Bell EJ. Serologic typing of rickettsiae of the spotted fever group by microimmunofluorescence. J Immunol. 1978;121:1961-8.

33. La Scola B, Raoult D. Laboratory diagnosis of rickettsioses: current approaches to diagnosis of old and new rickettsial diseases. J Clin Microbiol. 1997:35:2715-27.

34. Piranda EM, Faccini JLH, Pinter A, Saito TB, Pacheco RC, Hagiwara MK, Labruna MB. Experimental infection of dogs with a Brazilian strain of Rickettsia rickettsii: clinical and laboratory findings. Mem Inst Oswaldo Cruz. 2008:103:696-701.

35. Socolovschi C, Audoly G, Raoult D. Connection of toxin-antitoxin modules to inoculation eschar and arthropod vertical transmission in Rickettsiales. Comp Immunol Microbiol Infect Dis. 2013;36:199-209.

36. La Scola B, Bechah Y, Lepidi H, Raoult D. Prediction of rickettsial skin eschars in humans using an experimental guinea pig model. Microb Pathog. 2009;47:128-33.

37. Fournier PE, Raoult D. Current knowledge on phylogeny and taxonomy of Rickettsia spp. Ann N Y Acad Sci. 2009;1166:1-11.

38. Labruna MB, McBride JW, Bouyer DH, Camargo LMA, Camargo EP, Walker $\mathrm{DH}$. Molecular evidence for a spotted fever group Rickettsia species in the tick Amblyomma longirostre in Brazil. J Med Entomol. 2004;41:533-7.

39. Regnery RL, Spruill CL, Plikaytis BD. Genotypic identification of rickettsiae and estimation of intraspecies sequence divergence for portions of two rickettsial genes. J Bacteriol. 1991;173:1576-89.

40. Roux V, Fournier PE, Raoult D. Differentiation of spotted fever group rickettsiae by sequencing and analysis of restriction fragment length polymorphism of PCR-amplified DNA of the gene encoding the protein rOmpA. J Clin Microbiol. 1996:34:2058-65.

41. Roux V, Raoult D. Phylogenetic analysis of members of the genus Rickettsia using the gene encoding the outer-membrane protein rOmpB (ompB). Int J Syst Evol Microbiol. 2000;50:1449-55.

\section{Submit your next manuscript to BioMed Central and we will help you at every step:}

- We accept pre-submission inquiries

- Our selector tool helps you to find the most relevant journal

- We provide round the clock customer support

- Convenient online submission

- Thorough peer review

- Inclusion in PubMed and all major indexing services

- Maximum visibility for your research

Submit your manuscript at www.biomedcentral.com/submit 